\title{
CRISIS DE REPRODUCCIÓN SOCIAL Y PANDEMIA*
}

\author{
Leonardo Raffo a \\ Edwin Arbey Hernández
}

"DOI: https://doi.org/10.18601/01245996.v25n10. Buena parte de las ideas expuestas en este artículo se presentaron en el IV Seminario Internacional de Desarrollo y Territorio realizado en la Universidad de la Salle, Bogotá, a comienzos de mayo de 2020. Agradecemos los comentarios de los asistentes al seminario, así como las sugerencias de la epidemióloga Diana Maritza Jurado y del profesor Andrés García Trujillo. Recepción: 18-08-2020, modificación final: 30-04-2021, aceptación: 02-06-2021. Sugerencia de citación: Raffo, L. y Hernández, E. A. (2021). Crisis de reproducción social y pandemia. Revista de Economía Institucional, 23(45), 203-225.

${ }^{a}$ Economista y Magíster en Economía Aplicada. Profesor titular y miembro del Grupo de Investigación de Conflicto, Aprendizaje y Teoría de Juegos y del Grupo de Investigación de Desarrollo Económico, Crecimiento y Mercado Laboral de la Universidad del Valle, Cali, Colombia, [leonardo.raffo@ correounivalle.edu.co], [https://orcid.org/0000-0001-6087-535X].

${ }^{b}$ Economista y Magíster en Economía Aplicada. Miembro del Grupo de Investigación de Desarrollo Económico, Social y Cultural de la Universidad del Valle, Cali, Colombia, [edwin.hernandez@correounivalle.edu.co], [https:// orcid.org/0000-0002-5919-7659]. 


\section{Crisis de reproducción social y pandemia}

Resumen Este articulo analiza las dinamicas de acumulacion capitalista que han incidido en la extension de la pandemia de COVID-19 y en la magnitud de sus efectos sobre la economia y las sociedades. Argumenta que para entender la crisis economica y social causada por la pandemia es indispensable tener en cuenta la contradicción entre la acumulacion de capital y los procesos de reproduccion social, que se ha profundizado en los ultimos anos, junto con el resurgimiento de movimientos populistas y nacionalistas en diversos paises.

Palabras clave: pandemia, crisis de reproduccion social, biovigilancia, capitalismo, globalizacion; JEL: F63, F68, I12, I14, P10, P16

\section{Social reproduction crisis and pandemic}

Abstract This article examines how the dynamics of capital accumulation have shaped the development and socio-economic effects of COVID-19. We argue that in order to properly understand the social and economic crisis unleashed by the pandemic, it is necessary to consider the contradiction between capital accumulation and the processes of social reproduction, which have deepened over recent years, as well as the resurgence of populist and nationalist movements around the world.

Keywords: pandemic, crisis of social reproduction, biomonitoring, capitalism, globalization; JEL: F63, F68, I12, I14, P10, P16

\section{Crise de reprodução social e pandemia}

Resumo Este artigo analisa a dinâmica da acumulação capitalista que influenciou a propagação da pandemia COVID-19 e a magnitude de seus efeitos na economia e nas sociedades. Ele defende que, para compreender a crise econômica e social provocada pela pandemia, é fundamental levar em conta a contradição entre a acumulação de capital e os processos de reprodução social, que se aprofundou nos últimos anos, junto com o ressurgimento de grupos populistas e populistas. movimentos nacionalistas em vários países.

Palavras-chave: pandemia, crise de reprodução social, biovigilância, capitalismo, globalização; JEL: F63, F68, I12, I14, P10, P16 
Hn los últimos años muchos países han sufrido una progresiva Cdesaceleración económica y un creciente deterioro de las condiciones laborales de la mayoría de los asalariados, más intenso que el ocasionado décadas atrás por el modelo neoliberal. El aumento de la desigualdad ha llevado al resurgimiento de políticas proteccionistas en regímenes populistas y nacionalistas como el de Donald Trump en Estados Unidos y el de Jair Bolsonaro en Brasil, que negaron la gravedad de la pandemia, agudizaron la crisis económica y elevaron la pérdida de empleos y las muertes por millón de habitantes (Chicaíza, García y Urrea,2021). Es paradójico que la élite económica favorecida por las políticas neoliberales hoy lidere "causas nacionales"(Gonzalez y Carroll, 2017). El retorno del proteccionismo ha detonado guerras comerciales, como la que se inició en marzo de 2018 entre Estados Unidos y China, y se apaciguó en enero de 2020 con la firma de un acuerdo comercial entre ambos países.

En esa coyuntura estalló la pandemia, que produjo un cataclismo en la economía mundial. El coronavirus y las medidas de confinamiento y estado de excepción que se han aplicado en la mayoría de los países han llevado al cese o a la interrupción de gran parte de las actividades económicas que han provocado una caída del crecimiento global sin precedentes desde la gran recesión de 2008 y la gran depresión de la década de 1930. ¿De qué manera el sistema capitalista acentuó la extensión de la pandemia y agravó sus efectos? ¿Cuáles pueden ser los efectos de la pandemia sobre el capitalismo y la globalización?

Este artículo analiza los factores económicos asociados al desarrollo de la pandemia, y sus efectos en las economías y las sociedades. El desmonte de las políticas sociales en un contexto de enorme desigualdad del ingreso y concentración de la riqueza es esencial para comprender el fuerte impacto negativo del coronavirus y el mal manejo sanitario de la pandemia. La hipótesis de partida es que "la contradicción entre la acumulación global de capital y la provisión de condiciones estables y progresivas para la reproducción social” o, en palabras de Nancy Fraser (2016), la contradicción social-reproductiva del capitalismo, se ha acentuado en las últimas décadas (ver Bakker, 2020; Bakker y Gill, 2003, 2019). La pandemia ha develado con suma claridad el fracaso del modelo neoliberal, incluso para garantizar el funcionamiento estable del capitalismo en el presente y en el futuro.

El artículo consta de cinco secciones. En la primera se expone el concepto de reproducción social como marco analítico. En la segunda se describe la fase actual del capitalismo y sus implicaciones en algunos procesos clave para la reproducción social. En la tercera se 
analizan los factores económicos que han incidido en el desarrollo de la COVID-19 y en sus efectos directos e indirectos. En la cuarta se reflexiona sobre el posible fin de la globalización neoliberal tal como la conocemos. En la última se exponen las conclusiones.

\section{LA REPRODUCCIÓN SOCIAL}

La reproducción social incluye los procesos, las instituciones y las capacidades sociales que garantizan la reproducción de la fuerza de trabajo y el cuidado de los individuos en toda sociedad: "el nacimiento y crianza de los niños, el cuidado de los amigos y miembros de las familias, el sostenimiento de los hogares y comunidades más amplias, y el mantenimiento de conexiones más generales" (Fraser, 2016, p. 99). Como ella señala, se trata de actividades que incluyen trabajo afectivo y material, casi siempre realizadas sin remuneración en el capitalismo, aunque pueden ser remuneradas. En la historia y en las diversas sociedades las actividades de reproducción social han sido una tarea desempeñada en su mayoría por las mujeres, y en algunos casos por hombres (Fraser, 2016).

Siguiendo a Bakker y Gill (Bakker y Gill, 2003, 2019; Gill, 2015; Bakker, 2020), en este artículo partimos de un concepto amplio de reproducción social que abarca todos "los procesos sociales, mecanismos e instituciones sobre los que se construyen comunidades y sociedades, así como el poder y la producción” (Bakker y Gill, 2003, p. 3). Para estos autores, el Estado determina en gran medida la regulación de la reproducción biológica, de la fuerza laboral y de las prácticas sociales de cuidado, socialización y satisfacción de las necesidades humanas. En las sociedades capitalistas, la reproducción social no se circunscribe al cuidado, sino que abarca la reproducción de la vida y de las relaciones capitalistas, es decir, de los trabajadores y de la fuerza de trabajo (Mezzadri, 2019).

Así, la reproducción social asegura la existencia continua de la sociedad capitalista. Según Munro, el hogar de la clase trabajadora contribuye a la acumulación y está implicado en la reproducción social de varias formas: 1) Sus miembros que trabajan en forma remunerada contribuyen a la acumulación porque su salario es menor que el valor producido por su fuerza de trabajo en la jornada laboral. 2) El hogar es el lugar primario de crianza de las nuevas generaciones de trabajadores. 3) El hogar adquiere mercancías como insumos para su reproducción, realizando así un valor excedente en forma de beneficio. 4) Sus miembros pueden tener trabajo adicional no remunerado, 
bien sea para firmas a las que adquieren bienes y servicios o para el Estado en forma de trabajo voluntario. 5) También contribuye a la reproducción social al pagar impuestos (Munro, 2019).

E1 Estado, las instituciones políticas y sociales y las firmas también contribuyen a la reproducción social. De hecho, la interdependencia entre hogares, firmas capitalistas y Estado en los procesos de producción es la que garantiza la reproducción de la sociedad capitalista como un todo (Munro, 2019).

La contradicción social-reproductiva del capitalismo o, en otras palabras, la contradicción entre acumulación de capital y reproducción social subyace a cualquier sociedad capitalista:

Por una parte, la reproducción social es una condición que hace posible la acumulación sostenida del capital; por otra parte, la tendencia [... a] una acumulación ilimitada de capital tiende a desestabilizar el proceso de reproducción social en el que se basa (Fraser, 2016, p. 100).

Esta contradicción es entonces inherente al sistema capitalista, pero ha tenido diferentes manifestaciones en cada una de sus formas históricas específicas. Como veremos, el punto clave es que en su fase actual, a la que Fraser llama "capitalismo financiarizado", la contradicción social-reproductiva se ha acentuado y, además, se ha conjugado con otras crisis -económica, política y ecológica-, dando lugar a una crisis general (ibíd., 2016).

\section{ACUMULACIÓN FLEXIBLE, CRISIS DE REPRODUCCIÓN SOCIAL Y NUEVOS POPULISMOS}

Para entender el contexto global en el que llegó la crisis causada por el nuevo coronavirus es necesario dar cuenta de la fase actual del capitalismo y sus implicaciones: sobre la desigualdad económica, la reproducción social y el ascenso de líderes populistas autoritarios.

La desaceleración económica de las últimas dos décadas ha sido una característica en la mayoría de las economías, junto a las persistentes altas tasas de desempleo en algunas economías avanzadas y emergentes. La gráfica 1 muestra que, con excepción de India, la tasa de crecimiento tendió a disminuir entre 2000 y 2018. En China y Rusia se redujo en términos reales del 8,5\% al 6,6\% y del 10\% al $2,3 \%$, respectivamente. A nivel global, se redujo del 4,4\% en 2000 al $3,1 \%$ en 2018. En las economías desarrolladas la tasa de crecimiento real anual pasando del 4,7\% al 3,2\% y en las economías en desarrollo, del 4,1\% al 3,1\% (Banco Mundial, 2020). 
La economía mundial no se recuperó totalmente de la crisis provocada por la gran recesión. La reestructuración diseñada en ese entonces se centró en planes de salvamento del sector financiero y de otros sectores estratégicos (Malinowitz, 2010; Unctad, 2010), una mayor regulación financiera para controlar el crecimiento desmesurado de las inversiones de alto riesgo (en particular, la volátil demanda de acciones de corto plazo y bonos basura) y la austeridad de los regímenes monetarios y fiscales (Gill, 2015; Krugman, 2012). Pero no se tomaron medidas de fondo que superaran los problemas sistémicos que vuelven frágiles e inestables a las economías, tanto por el lado de la oferta agregada como por el de la demanda agregada.

Gráfica 1

Tasa de crecimiento del PIB real anual

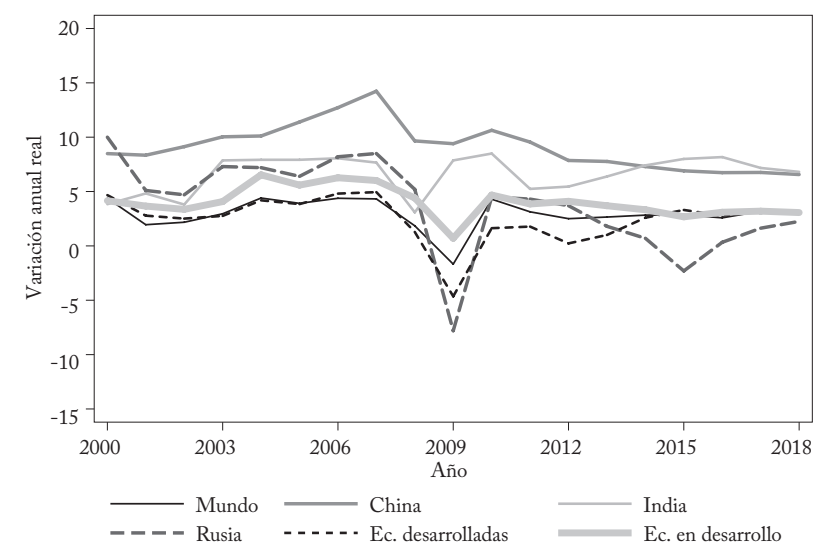

Fuente: indicadores del Banco Mundial y cálculos propios.

Después de la gran recesión y de las medidas de política adoptadas, en vez de que surgiera una nueva fase de acumulación se profundizó el modelo de acumulación flexible que empezó a consolidarse a finales de los años setenta con la globalización neoliberal (Harvey, 2008; Vargas, 2010) ${ }^{1}$. ¿De qué manera? Desde comienzos de este siglo, la

${ }^{1}$ Este modelo se basa en una flexibilización laboral que busca reducir los costos laborales, mejorar el acople entre la muy variable demanda de trabajo y la disponibilidad de mano de obra en el corto plazo, y aumentar la eficiencia productiva. Mediante estrategias empresariales menos rígidas y restrictivas que las del fordismo, procura fomentar innovaciones y nuevos procesos productivos para aumentar la rotación del capital y de las mercancías, y así minimizar los inventarios, es decir, lograr inventarios just in time (Harvey, 2008). La difusión de este modelo ha tenido dos efectos: por un lado, como plantea Harvey, "las economías de escala buscadas con la pro- 
acumulación de capital empezó a ser jalonada en forma creciente por los sectores de servicios, dando lugar a la terciarización progresiva (gráfica 2) y la flexibilización laboral de las economías.

Se consolidó entonces el modelo de acumulación flexible centrado en la producción y comercialización vertiginosas y a escala mundial de servicios: turismo y hoteles, restaurantes, bares, cosmética, cirugía plástica, industria del entretenimiento, social media stars (influencers, youtubers, tuiteros), informática y telecomunicaciones (incluidos los big data y la inteligencia artificial). Junto a la digitalización de la producción y el comercio, que ha desplazado la economía industrial tradicional por la economía inmaterial, y aumentado la desigualdad (Preciado, 2020).

Gráfica 2

Producción y exportaciones de servicios en el siglo XXI
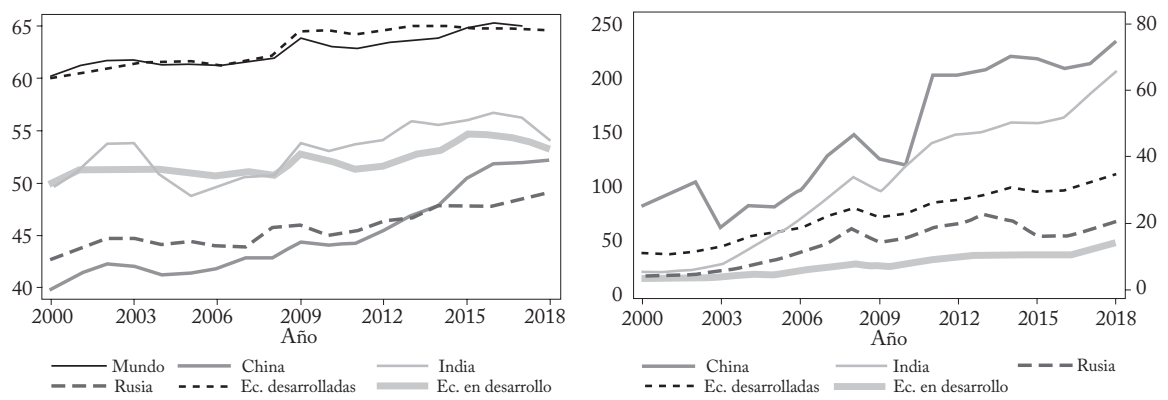

Producción de servicios como porcentaje del PIB; exportaciones de servicios en miles de dólares corrientes. Fuente: indicadores del Banco Mundial y cálculos propios.

E1 crecimiento de estos servicios y sectores fue jalonado por un consumo masivo más rentable que el tradicional, llamado por algunos autores "consumismo compensatorio". Sus usuarios suelen ser trabajadores calificados que tienen acceso a servicios como el turismo o a bienes de lujo en "compensación" por el aumento de su tiempo de trabajo o su mayor productividad (Gorz, 1991, 1994; Rubio, 2000; Harvey, 2020).

La profundización de la acumulación flexible ha aumentado la velocidad de rotación de capital (Harvey, 2008, 2020). Al mismo

ducción en masa fordista enfrentaron la posibilidad de manufacturar gran cantidad de bienes con menos costos en pequeñas series" (2008, p. 179), ampliando las posibilidades productivas de sectores tradicionales y nuevos. Por otro lado, la flexibilización de su aplicación debilitó las formidables estructuras sindicales que se consolidaron desde 1930 en las grandes potencias y sobre todo en Estados Unidos. 
tiempo, ha agravado algunos problemas sociales que han agudizado la contradicción entre acumulación de capital y reproducción social. Aunque en toda sociedad capitalista esta contradicción social-reproductiva está en el origen de la crisis del cuidado. Su agudización en la fase actual es resultado de dos procesos críticos: el mantenimiento de altos niveles de desigualdad del ingreso y de concentración de la riqueza, y el desmonte gradual del gasto público en educación y salud. Veamos por qué.

La acumulación flexible y la terciarización de la economía han elevado la desigualdad del ingreso a niveles muy altos en casi todos los países. La gráfica 3 muestra la evolución del índice de Gini en el periodo 2000-2018. Este se mantuvo en un alto nivel en Brasil, India y Rusia. En China se redujo hasta 2010. En los países en desarrollo, es alto pero decreciente, y en los países desarrollados ha aumentado desde el año 2000.

Gráfica 3

Desigualdad de los ingresos

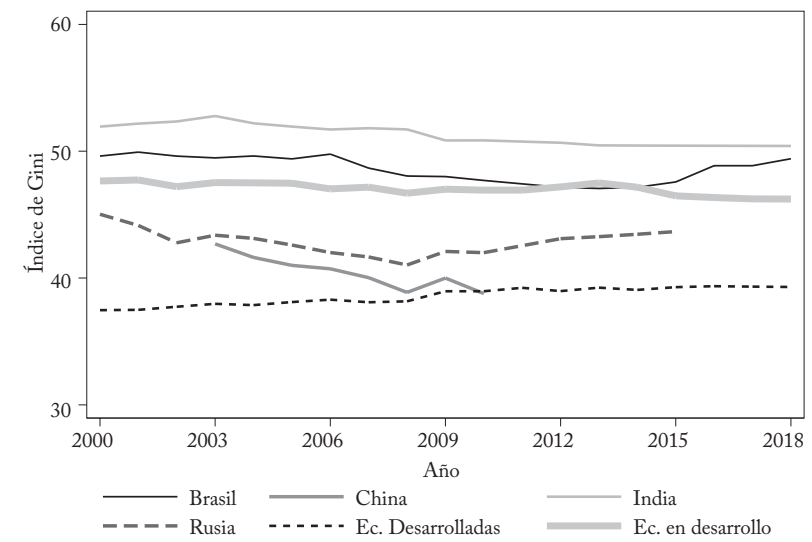

Fuente: datos de UTIP-Unido y cálculos propios.

En sus estudios empíricos del periodo 1988-2008 y del periodo 1990-2010, Lakner y Milanovic (2013, 2015) y Bourguignon (2015), respectivamente, encontraron que la desigualdad del ingreso dentro de los países creció y que la desigualdad interpersonal global del ingreso aumentó en la mayoría de los países ${ }^{2}$. Los resultados del estudio de Piketty (2014) sobre la distribución de la riqueza concuerdan con los

${ }^{2}$ Esta tiene en cuenta la desigualdad de las personas dentro de los países. Según Lakner y Milanovic (2015), capta la desigualdad de los ingresos de los individuos en todo el mundo tratándolos por igual independientemente 
de esos autores. Piketty sostiene que cuando la tasa de retorno del capital es mucho mayor que la tasa de crecimiento de la economía, la riqueza proveniente de herencias crece a tasas más altas que los ingresos. El resultado es una alta y creciente concentración del capital en manos de muy pocos individuos.

Desde un punto de vista sistémico, estos fenómenos distributivos reflejan la reducción progresiva de los ingresos salariales como porcentaje del producto total (Unctad, 2010; Bourguignon, 2015), debida a la flexibilización y la desregulación de los mercados laborales en la mayoría de los países. Tales fenómenos, junto a la terciarización, han propiciado el "consumismo compensatorio" por dos razones:

1) El crecimiento exponencial de la riqueza en unos pocos y la consolidación de una clase de trabajadores calificados -bien diferenciados de los no calificados-impulsaron el despegue de diversos servicios de lujo -de entretenimiento, cosméticos, restaurantes y hoteles-y de una franja importante del turismo internacional. 2) El crecimiento del crédito de consumo ha hecho posible que muchos trabajadores compensen sus bajos ingresos y accedan (endeudándose) a una amplia gama de bienes y servicios de "consumo compensatorio".

Como aduce Nancy Fraser (2016), la deuda ha cumplido un papel central en la fase actual puesto que es el instrumento través del cual el sistema financiero presiona a los Estados para recortar el gasto público y mantener la austeridad fiscal, y se colude con los inversionistas privados para extraer ganancias de los trabajadores. Así, el modelo de acumulación flexible y consumismo compensatorio ha aumentado la velocidad de rotación del capital, ha extendido sus límites de acumulación y ha precarizado a la mayor parte de la mano de obra, con efectos catastróficos sobre la reproducción social.

Además, ha provocado una crisis de las entidades de salud, cuidado, bienestar y subsistencia (Bakker y Gill, 2003, 2019; Gill, 2015; Bakker, 2020), por el desmonte de empresas públicas y la reducción de la inversión pública en salud y educación. La gráfica 4 muestra que en casi todos los países, el gasto público por estudiante de educación terciaria tiende a la baja desde el año 2000, salvo en Rusia, donde mantiene una tendencia creciente (Banco Mundial, 2020).

de su país de residencia. Para un análisis de la persistencia de los altos niveles de desigualdad, ver Raffo y Hernández (2021). 


\section{Gráfica 4}

Gasto público por estudiante en educación terciaria

(Porcentaje del PIB per cápita)

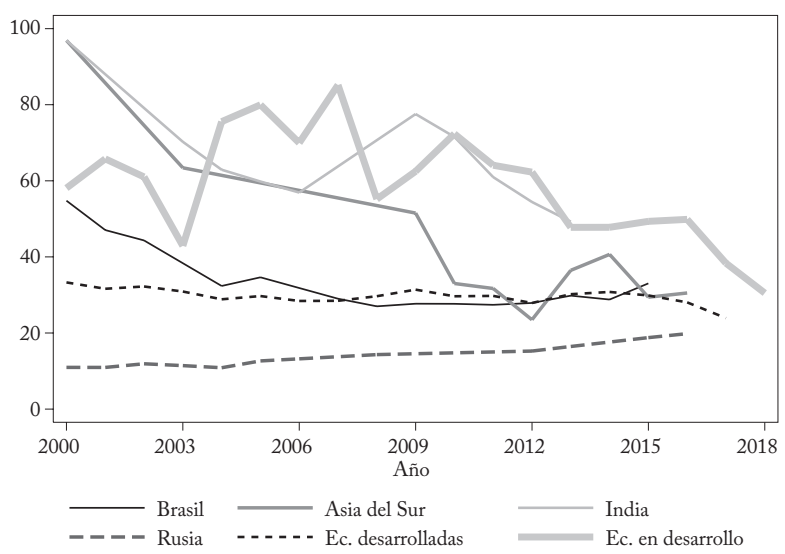

Fuente: indicadores del Banco Mundial y cálculos propios.

La gráfica 5 revela que solo en las economías desarrolladas tendió a crecer el gasto público en salud. En las demás se mantuvo constante o se redujo ligeramente, como en Rusia, que en el año 2000 invirtió el 9,7\% en salud y en 2017 redujo el al 8,8\% (Banco Mundial, 2020).

\section{Gráfica 5}

Gasto público en salud

(Porcentaje del gasto gubernamental)



Fuente: indicadores del Banco Mundial y cálculos propios.

Esta reducción pone de relieve la "contradicción entre el poder extendido del capital (y su protección por el Estado) y formas de re- 
producción social no solo sostenibles sino también progresivas para la mayor parte de la población mundial"3 (Bakker y Gill, 2003, p. 4).

Una consecuencia del aumento de la desigualdad y de la crisis de las instituciones de salud, cuidado, bienestar y subsistencia, es decir, de la crisis de reproducción social en la fase de acumulación flexible y consumismo compensatorio es el resurgimiento de movimientos populistas de izquierda y de derecha en muchos países. El populismo implica identificar y excluir a algún "otro" como enemigo que legitima una causa (Gonzalez y Carroll, 2020).

Algunos de esos movimientos populistas tienden a ser nacionalistas de derecha, como el encabezado por Donald Trump en Estados Unidos, que lo llevó a la presidencia en 2017; el de Jair Bolsonaro en Brasil y el de Rodrigo Duarte en Filipinas. Duarte ha mostrado un enorme desdén por los derechos humanos (ibíd.); hace unos meses se hizo célebre porque ordenó "disparar a matar" contra quienes violaran la estricta cuarentena (El Nuevo Día, 2020).

La aparición de los nuevos populismos también ha sido terreno fértil para el ascenso de movimientos contrarios al statu quo y al modelo neoliberal, así como para el contrapunteo de movimientos reaccionarios liderados por las élites neoliberales. Un movimiento contrario al statu quo es el del 15-M, conocido como "los Indignados", que irrumpió en España el 15 de mayo de 2011 exigiendo una democracia participativa, cuestionando el bipartidismo y el poder desmesurado del sector bancario y de los grandes conglomerados empresariales. Movimientos similares han aparecido y se han manifestado en otros países europeos, así como en Estados Unidos.

E1 resultado es una profunda crisis de legitimidad e inconformidad con el modelo imperante, que ha roto el consenso de las élites en torno al neoliberalismo (Gonzalez y Carrol, 2017). La necesidad de un nuevo consenso ha dado lugar al resurgimiento de populismos nacionalistas o de élites, aunque las nuevas élites nacionales fuesen grandes beneficiarias de la era neoliberal (ibíd.).

La problemática del periodo 2010-2020 revela dos aspectos importantes en la evolución del capitalismo contemporáneo: 1) el resurgimiento del nacionalismo y el populismo es una consecuencia del orden neoliberal, y no una antítesis surgida en el vacío (Gonzalez, 2018). El liberalismo de mercado no es incompatible con el autoritarismo y tampoco el nacionalismo con la globalización económica. 2)

${ }^{3}$ Para Bakker y Gill, “contradicción” es la aparición de elementos opuestos que crean disputas entre fuerzas sociales que pueden llevar a un cambio estructural. 
La persistencia de la globalización neoliberal ha provocado una crisis de la reproducción social que debería llevar a la reestructuración de las instituciones de salud, cuidado, bienestar y subsistencia. Según Bakker y Gill, las formas públicas y privadas de poder regulan los tres principales aspectos de la reproducción social: la reproducción biológica; la reproducción de la fuerza laboral, las prácticas sociales de cuidado, socialización y satisfacción de las necesidades humanas. Aquí es esencial una nueva política pública que proporcione salud, educación, bienestar y socialice el riesgo (Bakker, 1999; Bakker y Gill, 2003; UNDP, 1999).

\section{CAPITALISMO Y PANDEMIA}

La fase actual de acumulación flexible y consumismo compensatorio es el contexto en que surgió la pandemia de COVID-19. Ni la extensión de la pandemia ni sus consecuencias se pueden entender al margen de las dinámicas distributivas y de los problemas de reproducción social del esquema de acumulación actual. $\mathrm{Ni}$ siquiera el origen del virus está desligado de la dinámica del sistema socioeconómico.

De acuerdo con la evidencia disponible es muy probable que el nuevo coronavirus haya sido trasmitido a los seres humanos por algún animal (ver, p. ej., Barruti, 2021; Quammen, 2021; Shah, 2020), como sucede con todas las enfermedades de origen zoonótico. Aunque no hay certeza absoluta, el salto del virus y su mutación a la forma específica del SARS-CoV-2 fue un resultado de la comercialización de animales silvestres para ser consumidos como alimentos, quizá en mercados de Wuhan o en sus cercanías.

Muchos coronavirus pueden usar a los mamíferos como reservorios u hospedadores intermediarios, destacando entre ellos los murciélagos, en los que se facilita la recombinación y los eventos mutagénicos conducentes a una mayor diversidad genética de los virus (Consejo General de Colegios Farmacéuticos, 2020, p.3).

Sea cual haya sido el vector específico, el punto clave es que el detonador de estas enfermedades es "la relación abusiva y depredadora que establecemos con la naturaleza en general y con los otros animales en particular" (Barruti, 2020, p. 73). Debido a la destrucción acelerada de los hábitats naturales nuestras sociedades son cada vez más vulnerables a las pandemias (Shah, 2020; Wright, 2021). De modo que las circunstancias en las que el virus se convirtió en una amenaza global fueron resultado de la acción humana en el contexto actual.

Harvey argumenta que no hay desastres verdaderamente naturales porque el "capital modifica las condiciones ambientales de su 
reproducción, en un contexto de consecuencias involuntarias (como el cambio climático)" (2020, p. 82). E1 análisis de la pandemia y de sus efectos es muy complejo porque debe articular determinaciones sociales y naturales, y "captar los puntos donde esas dos determinaciones se cruzan para obtener las consecuencias” (Badiou, 2020, p.71). Para nuestro propósito quizá sea suficiente señalar que la destrucción del ambiente natural aumenta la probabilidad de enfermedades zoonóticas y que la densidad de la población es determinante en la transmisión de estas enfermedades.

La rápida propagación del virus no se debe únicamente a las características de su estructura molecular, que favorecen el contagio sino, quizá en mayor medida al enorme flujo de personas se mueven diariamente entre ciudades y países por trabajo o turismo, el cual es una consecuencia del modelo de acumulación flexible y consumismo compensatorio, y de la globalización. Como dice Paola Rosake, "el capitalismo estimula el turismo como consumismo compensatorio para los trabajadores"(Rosake, 2020,p. 325), quien además argumenta que la esencia del capitalismo global es la libre circulación de mercancías y personas, cuyas conexiones regionales y globales facilitan la propagación de enfermedades contagiosas (ibíd.). No deja de ser sorprendente, entonces, que solo hasta ahora la mayoría de los economistas, sociólogos y políticos haya empezado a entender que la veloz circulación de personas, bienes y servicios propicia las condiciones epidemiológicas para que patógenos con altas tasas de transmisión se propaguen rápidamente en todo el mundo.

E1 impacto a largo plazo de la pandemia dependerá de dos tipos de efectos: 1) de su efecto directo en la salud de los ciudadanos y del impacto en la economía por razones sanitarias; 2) de los efectos indirectos sobre la economía por las medidas de salud pública para contener el contagio. Ambos tipos dependen, por supuesto, de las estructuras sociales, políticas y económicas de cada país (Caduff, 2021; Chicaíza et al., 2021); en concreto, de tres factores relacionados con el sistema de reproducción social: el nivel de desarrollo de los sistemas de salud, el nivel de obediencia civil y el nivel de desigualdad.

\section{EFECTOS SOCIOECONÓMICOS DE LA PANDEMIA}

En la mayoría de los países, los efectos directos de la pandemia sobre la salud han sido desastrosos debido a las altas tasa de contagio y a las relativamente altas tasas de letalidad. E1 5 de marzo de 2021 se reportó un total de 116.348 .940 personas contagiadas en todo el 
mundo, 2.584.026 muertas y 65.695.020 recuperadas (Universidad de Johns Hopkins, marzo 6 de 2021). Con estas cifras, la tasa de letalidad es cercana al 2,2\%.

Pero más allá de las características del virus y del alto potencial de contagio ocasionado por las redes interconectadas globalmente, ¿qué explica esos preocupantes resultados? Por un lado, la falta de inmunidad, asociada a la alta mutación de los coronavirus y, hasta finales de 2020, la inexistencia de una vacuna que inmunice a los humanos contra la COVID-19. Para las autoridades sanitarias y los cuerpos médicos especializados era difícil controlar el primer elemento, salvo con medicamentos que redujeran la carga viral o atenuaran los síntomas graves de los pacientes afectados. Y, según algunos especialistas, no se ha desarrollado un tratamiento específico para este tipo de enfermedades:

Los interferones recombinantes o la rivabirina solo tienen efectos limitados en las infecciones por coronavirus. Recientemente se ha planteado la posibilidad de utilizar fármacos antirretrovirales (como lopinavir o ritonavir) o remdesivir - un fármaco antiviral desarrollado inicialmente para el tratamiento de la infección por el virus del ébola-, sin que por ahora se disponga de resultados concluyentes en torno a su eficacia (Consejo General de Colegios Farmacéuticos, 2020, p.4).

El segundo elemento -el desarrollo de una vacuna- depende de los incentivos de las farmacéuticas y de la inversión pública y privada en investigación y desarrollo. Aunque las vacunas contra la COVID-19 se desarrollaron en tiempo récord luego de la irrupción de la pandemia (Wright, 2020) ${ }^{4}$ utilizando un protocolo distinto del tradicional (Mella y Mohan, 2020), antes de la aparición del SARS-CoV-2 no había vacunas genéricas aprobadas para coronavirus tipo SARS o MERS, pese a las advertencias de tantos científicos que anunciaron la inminencia de nuevas pandemias. ¿Por qué razón? En los primeros años de este siglo se logró un significativo progreso en la investigación y desarrollo de vacunas para coronavirus (Zhou et al., 2020), pero no existían los incentivos económicos para que las farmacéuticas las produjeran y comercializaran en serie (Véliz et al., 2020; Caddy, 2020). Aparte de esto, cuando las vacunas desarrolladas contra el SARS-CoV-1 comenzaron a probarse en animales, se descubrió

\footnotetext{
${ }^{4}$ La secuencia genómica del virus se aisló el 10 de enero de 2020. Un día después se diseñaron las primeras proteínas modificadas necesarias para desarrollar la vacuna. Como señala Wright, el punto clave es que ya se sabía cómo alterar las "proteínas de pico" de otros coronavirus. Tan solo seis semanas después Moderna inició procesos de despacho de ampolletas de vacunas para experimentos clínicos (Wright, 2020).
} 
que provocaban sobrerreacciones inmunológicas, por lo que no se hicieron pruebas en humanos ni se prosiguieron los estudios porque el virus desapareció súbitamente (Roossinck, 2020) ${ }^{5}$. Aún no existen vacunas de referencia aprobadas para SARS-CoV-1 o MERS-CoV en humanos, $y$ hay pocas opciones para prevenir y tratar las patologías causadas por coronavirus (Véliz et al., 2020; Caddy, 2020).

Pero el problema más apremiante es lograr una rápida distribución de las vacunas contra la COVID-19 en todo el mundo. Aquí, el desmesurado poder político y económico actual de las grandes farmacéuticas cumple un papel central. Desde comienzos de los ochenta, y de la mano del sector financiero, la industria farmacéutica se convirtió en un pilar fundamental de la economía mundial, encabezada por unas pocas firmas con sede en las grandes potencias (Clasco, 2021a). Por ello, las big pharma son hoy un poderoso oligopolio que maneja la venta y la distribución de vacunas COVID-19 a costa de los gobiernos y la población de muchos países. Además, se ha acusado a la Organización Mundial de la Salud de estar colonizada por la industria farmacéutica:

Estos entramados son los que actualmente se reproducen y gobiernan el Fondo de Acceso Global para vacunas COVID-19 conocido como el mecanismo COVAX de la OMS [que] junto a la alianza GAVI y CEPI representan una trama donde se garantizan los derechos de "patentes" de las vacunas bajo la lógica de mercado y solo se comprometen a donar una porción "ínfima” que supone más un sentido de "beneficencia y caridad global” con el Sur que en un derecho colectivo ante la necesidad de inmunizar a 7.000 millones de personas (Clacso, 2021b, pp. 3-4).

El resultado es el predominio de los intereses privados sobre los de la población y una distribución inequitativa de las vacunas contra la COVID-19 entre las potencias económicas y los demás países, desconociendo que son un bien público global.

Además, el desmonte de los sistemas públicos de salud, causado por la privatización y las políticas de austeridad, redujo su infraestructura y su planta para responder a una pandemia, pese a la experiencia de pandemias recientes, como la del SARS y la del ébola. Así se eliminó "el superávit que se ocupaba de las capacidades que harían falta en una emergencia. La prevención ni siquiera era un área de trabajo tentadora para justificar formas de asociación pública-privada" (Harvey, 2020, p. 87).

5 Esta autora aduce que, aunque no se sabe con certeza porqué concluyó la epidemia de SARS-CoV-1 - lo que corrobora el carácter impredecible de los virus-, influyeron varios factores, entre ellos la estricta cuarentena de quienes estuvieron en contacto con individuos infectados e incluso el clima del verano. 
Las deficiencias de los sistemas de salud y el limitado acceso de los ciudadanos son claves para entender los efectos directos de la pandemia sobre la salud. Su desmonte gradual allanó el camino para que los peores números de muertes ocurrieran en países con baja capacidad instalada, con pocas UCI, y sin pruebas sistemáticas ni rastreo meticuloso de los contagiados y sus contactos, etc. (Chicaíza et al., 2021; Caduff, 2021). Chicaíza et al. demuestran que los países con peores indicadores económicos resultantes de la pandemia fueron los que hasta 2019 no tenían un sistema de salud robusto y su capacidad instalada era muy insuficiente para atender la emergencia, de modo que no podían ordenar cuarentenas tan estrictas.

El impacto en la economía es inmediato: afecta la salud de los trabajadores y empresarios y se reduce la actividad de todos los sectores, de modo que los gobiernos tienen que declarar estados de excepción (de emergencia sanitaria o económica) para enfrentar la crisis sanitaria, lo que implica nuevas necesidades de gasto público que se deben financiar con fuentes extraordinarias (mayor endeudamiento público y privado, nuevos impuestos, transitorios o permanentes, eliminación de exenciones y políticas de flexibilización cuantitativa.

Los efectos indirectos dependen de las medidas de salud pública que se adopten. En la mayoría de los países, el confinamiento, más que aplanar las curvas de contagio, busca postergar los picos de contagio para tener un margen que permita acondicionar clínicas, hospitales y centros de atención médica (algunos improvisados) para atender la demanda (en muchos casos masiva) de los enfermos de COVID-19. Es evidente que la necesidad de aplicar cuarentenas obedece a la imposibilidad de mitigar los efectos directos con otras estrategias, como el cerco epidemiológico apoyado por la biovigilancia digital, el autocuidado o la inmunidad de rebaño, que quizá no se alcance sin una aplicación masiva de vacunas.

El confinamiento frena abruptamente la actividad de muchos sectores, excepto de los que se requieren para producir, transportar y comercializar bienes y servicios de subsistencia como los alimentos y los servicios de salud, de los que se requieren para el funcionamiento y soporte de las redes de telecomunicaciones e internet, de las instituciones públicas y de todas las actividades que se realizan por teletrabajo sin presencia física, como parte de la educación y el entretenimiento. Los efectos del cierre temporal de la producción, la distribución y el consumo sobre los demás sectores son devastadores: la quiebra de numerosas empresas y el despido de trabajadores si los gobiernos no toman medidas oportunas y apropiadas. 
A este respecto caben dos consideraciones: 1) el confinamiento ha afectado más a los sectores que impulsan el "consumismo compensatorio" (ver, Rosake, 2020; Hiernaux, 2020; Fletcher, Murray, Blázquez y Blanco, 2020): el turismo, los restaurantes, los bares y el entretenimiento porque se realizan en espacios físicos, requieren el desplazamiento de los consumidores por espacios públicos y la interacción social. Así, los negocios que impulsaron el despegue de la economía después de la gran recesión están en entredicho, con graves consecuencias para el comportamiento de los mercados bursátiles y cambiarios; 2) el cierre de buena parte de la economía afecta más a las actividades que no admiten el teletrabajo: a trabajadores, comerciantes y propietarios de empresas medianas y pequeñas de franjas del comercio, restaurantes, bares, turismo y hoteles, construcción y manufacturas (ver Fletcher, Murray, Blázquez y Blanco, 2020; Mora, 2020; Dugarova, 2020).

Pero, aún más importante, la magnitud de los daños económicos y sociales es proporcional a la incidencia de la pobreza, en especial la pobreza urbana. El drama social es mayor en los países con mayores índices de pobreza, de desigualdad y falta de acceso a la seguridad social, donde la contradicción entre el capital y la reproducción social es más profunda.

Como señala Harvey, las repercusiones socioeconómicas de la pandemia son heterogéneas entre grupos sociales y comunidades. Las personas que cuidan enfermos y las que deben salir a la calle para realizar sus actividades pertenecen a ciertos géneros y etnias. Dugarova argumenta que la pandemia ejerce un fuerte impacto sobre los trabajos de cuidado no remunerado. Debido a la menor oferta formal e informal (incluida en esta última la ayuda de otros familiares), los padres que trabajan en casa, deben asumir el cuidado de sus hijos y asesorarlos en el aprendizaje escolar (virtual) (Dugarova, 2020). Además, los efectos sociales y económicos negativos sobre las mujeres son más fuertes: ha incrementado su inseguridad social, el trabajo de cuidado no remunerado y la violencia doméstica (UN Woman, 2020; UN, 2020).

La estructura social reforzada por la globalización, basada en la división entre quienes pueden viajar fácilmente alrededor del globo (los ricos propietarios del capital) y quienes tienden a localizarse en lugares fijos (Beck, 2008; Bauman, 2010), ayuda a entender los efectos heterogéneos de la pandemia. Mientras que los propietarios del capital y las clases medias tienen capacidad económica, riqueza y comodidades en casa suficientes para sobrellevar un confinamiento relativamente largo, las personas de bajos ingresos (en general, asa- 
lariados o trabajadores informales) no tienen medios suficientes ni siquiera para afrontar un breve confinamiento; son las que soportan la peor carga de la crisis y corren el mayor riesgo de contagio, es decir, las que más sufren la crisis de reproducción social.

La obediencia de los ciudadanos también es un determinante de la intensidad de los efectos indirectos de la pandemia, pues guarda relación con el rigor y la eficacia de las medidas de confinamiento. La mayor eficacia del distanciamiento social en sociedades que tienden a ser más obedientes reduce la duración de las cuarentenas y atenúa los efectos indirectos que afectan negativamente la reproducción social. En buena medida por esta razón, algunos países asiáticos han logrado contener la pandemia. En China, Corea, Hong Kong, Japón Singapur y Taiwán se confía más en el Estado; aunque tengan regímenes políticos muy distintos, por su tradición cultural tienen una mentalidad autoritaria y aceptan la vigilancia digital (Han, 2020). Tienden a ser más disciplinados en sus rutinas diarias y han podido enfrentar la pandemia con una vigilancia digital bajo estricto control del gobierno, mucho más eficaz que las medidas de encierro adoptadas en Occidente, más acordes a técnicas disciplinarias y de control arquitectónico modernas (Foucault, 2018). Son técnicas de biovigilancia digital, mediante las que el Estado controla la información digital privada de los individuos en tiempo real con ayuda de los big data y la inteligencia artificial, que Preciado denomina "técnicas farmacopornográficas" y hacen énfasis

en la detección individual del virus a través de la multiplicación de los tests y de la vigilancia digital constante y estricta de los enfermos a través de sus dispositivos informáticos móviles. Los teléfonos móviles y las tarjetas de crédito se convierten aquí en instrumentos de vigilancia que permiten trazar los movimientos del cuerpo individual (Preciado, 2020, p. 177).

En Corea del Sur, por ejemplo, se adoptó una estrategia llamada "busca, controla y trata", que identifica y confina en forma obligatoria a los portadores del virus, cuyo punto de partida son las pruebas masivas para detectar casos positivos, y hacerles un seguimiento sistemático con técnicas de monitoreo que procesa la información de los celulares en forma continua (El Nuevo Siglo, 2020). Hong-Kong, Israel, Japón, Singapur y Taiwán adoptaron estrategias similares.

\section{¿EL FIN DE LA GLOBALIZACIÓN TAL COMO LA CONOCEMOS?}

La pandemia ha causado una crisis económica global sin precedentes desde la gran depresión. Pero la crisis sanitaria y social que ha oca- 
sionado ha puesto de relieve la gran debilidad del sistema capitalista actual para enfrentar esta y próximas pandemias, aunque solo es la punta del iceberg: el problema de fondo es la crisis de reproducción social que viene desde hace unas décadas y se agravó después de la gran recesión. Esta crisis solo se dejará atrás si se supera el neoliberalismo y se da paso a una nueva fase acumulación. La pandemia ha demostrado el fracaso del modelo neoliberal para mantener un funcionamiento pleno y estable del sistema económico ante desastres, guerras o pandemias, y que causa crisis que ponen en peligro la vida de millones de personas.

La crisis solo se superará si se hacen cambios de fondo que reconfiguren las estructuras sociales, económicas y políticas que dan soporte al sistema, es decir de parte de las instituciones sobre las que se construye la comunidad, la sociedad, el poder y la producción, y más en particular, de las que sirven de base a los sistemas de salud, educación e investigación científica. En el proceso de reestructuración la inversión pública en salud, educación e investigación y desarrollo debe tener un papel esencial, y en la provisión de esta clase de servicios se deben impulsar saltos tecnológicos que estén a tono con los avances en la ciencia y la informática.

Las medidas de estado de emergencia económica y sanitaria que hasta ahora ha adoptado la mayoría de los países, basadas en esquemas cortoplacistas de flexibilización monetaria, rescate financiero y salvamento de algunos sectores estratégicos no son suficientes, pues aplican "mayores dosis del mismo remedio para calmar los síntomas sin remediar la enfermedad". En la nueva fase, el Estado no se debe limitar a proteger el poder extendido del capital; debe garantizar una reproducción social progresiva acorde un poder limitado del capital, así como la sostenibilidad ecológica en el corto y en el largo plazo (Bakker, 2020). Por ello es necesario abandonar los preceptos de la globalización neoliberal y adoptar un nuevo modelo productivo distinto del de acumulación flexible y consumismo compensatorio. Solo así se podrá superar la contradicción entre acumulación de capital y reproducción social que se ha agudizado en las últimas décadas. Al inicio de la nueva fase capitalista quizá disminuya la velocidad de rotación del capital por el cambio estructural orientado al mayor desarrollo de los sectores intensivos en investigación y desarrollo, así como de la educación y la salud.

La pandemia no llevará el colapso del sistema capitalista sino a su posible reconfiguración, y quizá al fin de la globalización tal como la hemos conocido en las últimas décadas. Es posible, entonces, que 
el "consumo compensatorio" pierda vigencia e importancia frente al de servicios intensivos en tecnología y capital humano ligados a la educación, la investigación y el desarrollo, la informática, la infraestructura de telecomunicaciones y la inteligencia artificial.

Es posible que en el corto plazo se intensifiquen las medidas proteccionistas que ya aplican algunos países, cuyo resultado sería una reducción del comercio de bienes y servicios aun mayor que la caída de la producción mundial. En el mediano y largo plazo los flujos comerciales se recuperarían, pero quizá no llegarían a los niveles anteriores a la pandemia, y tendrán una composición distinta, pues el comercio digital seguirá ganando terreno frente al comercio material.

\section{CONCLUSIÓN}

En la reconfiguración del sistema capitalista podrían jugar un papel determinante cuatro procesos distintos pero imbricados: 1) el diseño y la aplicación de políticas sociales y redistributivas ambiciosas que frenen la desigual distribución del ingreso y de la riqueza característica de las últimas décadas; 2) la reestructuración de parte de las instituciones y procesos que dan forma y soporte a los sistemas de salud, educación e investigación científica. 3) el surgimiento de un nuevo espectro de modelos políticos, que iría de nuevas versiones de la democracia liberal tradicional a regímenes autoritarios nacionalistas. Los nuevos modelos políticos darían continuidad al complejo proceso de resurgimiento del nacionalismo y el populismo; y 4) la reconversión tecnológica centrada en la digitalización y desmaterialización de la producción, en la que la inteligencia artificial y los big data tienen un papel central.

La crisis económica y social desatada por la pandemia demuestra el fracaso del modelo neoliberal para sostener la reproducción social en situaciones difíciles que provocan crisis que ponen en peligro la vida de millones de seres humanos. E1 problema es que los desastres naturales y la destrucción de los ecosistemas serán cada vez más frecuentes en un futuro no muy lejano, lo que convertiría al sistema actual en una distopía total. Ha llegado el momento de imaginar y poner en marcha modelos económicos y políticos que den inicio a nuevas historias.

\section{REFERENCIAS BIBLIOGRÁFICAS}

Badiou, A. (2020). Sobre la situación epidémica. En P. Amadeo (ed.), Sopa de Wuhan, pensamiento contemporáneo en tiempos de pandemias (pp. 67-78). La Plata: Editorial ASPO. 
Bakker, I. (1999). Neoliberal governance and the new gender order. Working papers, 1(2), 49-59.

Bakker, I. (2020). Variegated social reproduction in neoliberal times: Mainstream silences, feminist interventions. Nordic Journal of Feminist and Gender Research, 28(2), 167-172.

Bakker, I. y Gill, S. (2003). Global political economy and social reproduction. En I. Bakker y S. Gill (eds.), Power, production and social reproduction: Human in/security in the global political economy (pp. 3-16). Londres: Macmillan Palgrave.

Bakker, I., y Gill, S. (2019). Rethinking power, production, and social reproduction: Toward variegated social reproduction. Capital E Class, 43(4), 503-523.

Banco Mundial. (2020). Datos de libre acceso del Banco Mundial, [https:// datos.bancomundial.org/].

Barruti, S. (2021). Coronavirus y granjas industriales. Nuggets y murciélagos: cómo cocinamos las pandemias de hoy. Revista de Economía Institucional, 23(44), 71-79.

Bauman, Z. (2010). La globalización. Consecuencias humanas [1998]. Buenos Aires: Fondo de Cultura Económica,

Beck, U. (2008). ¿¿ué es la globalización? [1998]. Barcelona: Paidós.

Clacso (2021a). Covid-19 e industria farmacéutica global, [https://www. clacso.org/covid-19-e-industria-farmaceutica-global/]

Clacso (2021b). Las vacunas como bien público global y cuestión de soberanía sanitaria regional, [https://www.clacso.org/las-vacunas-como-bien-publico-global-y-cuestion-de-soberania-sanitaria-regional/].

Caddy S. (2020). Developing a vaccine for covid-19, [https://doi. org/10.1136/bmj.m1790].

Consejo General de Colegios Farmacéuticos. (2020). Informe Técnico, Coronavirus: COVID-19. [http://repositorio.uasb.edu.bo/hand1e/54000/1116].

Chicaíza B. L., García M., M. y Urrea I, L. (2021). ¿Economía o salud? Un análisis global de la pandemia de COVID-19. Revista de Economía Institucional, 23(44), 171-194.

Dugarova, E. (2020). Unpaid care work in times of the covid-19 crisis: Gendered impacts, emerging evidence and promising policy responses, [www.bollettinoadapt.it/wp-content/uploads/2020/11/Duragova. Paper_.pdf].

El Nuevo Día. (2020). El presidente de Filipinas ordena matar a los que violen la cuarentena, 1 de abril.

El Nuevo Siglo. Países con mejor diligencia frente al coronavirus, 6 de mayo.

Ella, K. M. y Mohan, V. K. (2020). Coronavirus vaccine: Light at the end of the tunnel. Indian Pediantrics, 57, 407-410.

Fletcher, R., Murray, I., Blázquez, M. y Blanco, A. (2020). Turismo, decrecimiento y la crisis del COVID-19. Alba Sud, [http://www.albasud. org/blog/es/1196/turismo-decrecimiento-y-la-crisis-del-covid-19].

Foucault, M. (2018). Vigilar y castigar: nacimiento de la prisión [2009]. México DF: Siglo XXI. 
Fraser, N. (2016). Contradictions of capital and care. New Left Review, $100,99-117$.

Gill, S. (2015). Global organic crisis and geopolitics, [http://stephengill. $\mathrm{com} /$ news/2015/08/globalorganic-crisis-and-geopolitics.html].

Gonzalez V., R. (2020). The liberal peace fallacy: violent neoliberalism and the temporal and spatial traps of state-based approaches to peace. Territory, Politics, Governance, 8(1), 100-116.

Gonzalez V. R. y Carroll, T. (2017). Politics after national development: Explaining the populist rise under late capitalism. Globalizations, 14(6), 991-1013.

Gorz, A. (1991). Metamorfosis del trabajo. Búsqueda de sentido. Critica de la razón económica. Madrid: Sistema.

Gorz, A. (1994). Ecología política. Expertocracia y autolimitación. Nueva Sociedad, 134, 32-41.

Han, B. (2020). La emergencia viral y el mundo de mañana. En P. Amadeo (ed.), Sopa de Wuhan, pensamiento contemporáneo en tiempos de pandemias (pp. 97-112). La Plata: Editorial ASPO.

Harvey, D. (2008). La condición de la posmodernidad: investigación sobre los orígenes del cambio cultural. Buenos Aires-Madrid: Amorrortu editores.

Harvey, D. (2020). Política anticapitalista en tiempos de COVID-19. En P. Amadeo (ed.), Sopa de Wuhan, pensamiento contemporáneo en tiempos de pandemias (pp. 79-96). La Plata: Editorial ASPO.

Hiernaux, Daniel (2020) "El amargo despertar del turismo mexicano pos-COVID-19”. En M. Simancas C., R. Hernández M. y R. Padrón F. (coords.). Turismo pos-COVID-19 Reflexiones, retos y oportunidades. Universidad de La Laguna, Canarias.

Krugman, P. (2012). The austerity debacle. The New York Times, 29 de enero.

Malinowitz, S. S. (2010). Obamaismo: la fase superior de la financiarización. En J. Estrada (comp.). El impacto de la crisis: tendencias y perspectivas del capitalismo contemporáneo (pp. 111-123). Bogotá: Universidad Nacional de Colombia.

Mezzadri, A. (2019). On the value of social reproduction: Informal labour, the majority world and the need for inclusive theories and politics. Radical Philosophy, 2(4), 33-41.

Lakner, C. y Milanovic, B. (2013). Global Income Distribution: From the Fall of the Berlin Wall to the Great Recession. In The World Bank Policy Research Working Paper, n. ${ }^{\circ}$ 6719. The World Bank, Development Research Group, Poverty and Inequality Team.

Lakner, C. y Milanovic, B. (2015). La distribución global del ingreso de la caída del Muro de Berlín a la gran recesión. Revista de Economía Institucional, 17(32), 71-128.

Mora, J. J. (2020). El efecto del coronavirus (COVID-19) sobre el mercado laboral en la ciudad de Cali. Icesi Economics, 11, 1-19.

Moraga V., A., Arenas L., D. et al. (2020). Análisis de inmunogenicidad y perfil de seguridad de vacunas contra el SARS-CoV-2 en ensayos clínicos de fase I/II. Revista Médica del Maule, 35(1), 18-24.

Munro, K. (2019). "Social reproduction theory", social reproduction, and household Production. Science E Society, 83(4), 451-468. 
Piketty, T. (2014). Capital in the Twenty-First Century. Cambridge: Harvard University Press.

Preciado, P. B. (2020). Aprendiendo del virus. En P. Amadeo (ed.), Sopa de Wuhan, pensamiento contemporáneo en tiempos de pandemias (pp. 163185). La Plata: Editorial ASPO.

Quammen, D. (2021). Por qué no estábamos preparados para el coronavirus. Revista de Economia Institucional, 23(44),53-70.

Raffo L., L., y Hernández G., E. (2021). Comercio internacional, prosperidad y desigualdad en la globalización. Apuntes del Cenes, 4O(71),135-166.

Rosake, P. (2020). Turismo y COVID-19: aportes de la geografía para un abordaje complejo. Cardinalis, 8(15), 319-334.

Roossinck, M. J. (2020). The mysterious disappearance of the first SARS virus, and why we need a vaccine for the current one but didn't for the other. The Conversationhttps://theconversation.com/us].

Rubio G., R. (2000). Lecturas críticas en torno al futuro del trabajo y el empleo. Reflexiones sobre los elementos presentes en las ideas de André Gorz. Biblio $3 W$. Revista Bibliográfica de Geografía y Ciencias Sociales, [www.ub.edu/geocrit/b3w-250.htm].

Shah, S. (2020). Contra las pandemias, la ecología. Le Monde Diplomatique, 2, [https://mondiplo.com/contra-las-pandemias-la-ecologia].

UN. (2020). The impact of COVID-19 on women. Policy Brief. Nueva York: United Nations.

UN Women. (2020). COVID-19 and ending violence against women and girls. Brief. Nueva York: UN Women.

UNDP. (1999). Human development report, 1999. Nueva York: Oxford University Press.

Unctad (2010). International trade after the economic crisis: Challenges and new opportunities. ONU, [https://Unctad.org/system/files/ official-document/ditctab20102_en.pdf].

Universidad Johns Hopkins. (2020). Dashboard by the Center for Systems Science and Engineering. CRC, [https://coronavirus.jhu.edu/ map.html].

Vargas A. (2010). E1 retorno del Estado: ¿hacia un posneoliberalismo? En J. Estrada (comp.). El impacto de la crisis: tendencias y perspectivas del capitalismo contemporáneo (pp. 125-133). Bogotá: Universidad Nacional de Colombia.

Wright, L. (2021). The plague year. The mistakes and the struggles behind America's coronavirus tragedy. The New Yorker, A Reporter at Large [https://www.newyorker.com/magazine/2021/01/04/the-plague-year].

Zhou, P., Li, Z. et al. (2021). Research progress and challenges to coronavirus vaccines development. Journal of Medical Virology, 9(32), 741-754. 